\title{
Territory choice during the breeding tenure of male sedge warblers
}

\author{
Tadeusz Zając • Wojciech Bielański • Wojciech Solarz
}

Received: 21 February 2011 /Revised: 28 July 2011 / Accepted: 2 August 2011 /Published online: 13 September 2011

(C) The Author(s). This article is published with open access at Springerlink.com 2011

\begin{abstract}
A territorial male can shift the location of its territory from year to year in order to increase its quality. The male can base its decision on environmental cues or else on its breeding experiences (when territory shift is caused by breeding failure in previous seasons). We tested these possible mechanisms of territory choice in the sedge warbler (Acrocephalus schoenobaenus), a territorial migrating passerine that occupies wetlands. This species bases its territory choices on an environmental cue: tall wetland vegetation cover. We found that the magnitude of territory quality improvement between seasons (measured as the area of tall wetland vegetation) increased throughout the early stages of a male's breeding career as a result of territory shifts dependent on the earliness of arrival. The distance the territory was shifted between seasons depended negatively on the previous year's territory quality and, less clearly, on the previous year's mating success. On the other hand, previous mating or nesting success had no influence on territory quality improvement between seasons as measured in terms of vegetation. The results imply that tall wetland vegetation is a long-term, effective environmental cue and that a preference for territories in which this type of landcover prevails has evolved into a rigid behavioral mechanism, supplemented by short-term individual experiences of breeding failure.
\end{abstract}

Keywords Territory fidelity · Environmental cues · Territory quality $\cdot$ Arrival date $\cdot$ Age $\cdot$ Ecological trap $\cdot$ Site tenacity

Communicated by C. Brown

T. Zając $(\bowtie) \cdot$ W. Bielański $\cdot$ W. Solarz

Institute of Nature Conservation, Polish Academy of Sciences,

A1. Mickiewicza 33,

31-120 Kraków, Poland

e-mail: tzajac@iop.krakow.pl

\section{Introduction}

Settlement of individuals within a habitat is crucial to individual fitness and population dynamics (Pulliam and Danielson 1991; Rodenhouse et al. 1997; McPeek et al. 2001). If some territories guarantee production of offspring to be recruited to the breeding population, whereas other territories will not even favor mate attraction, it is obvious that each individual should occupy the best territory possible. This implies that an individual should not necessarily return to the same territory but should actively search for a better one for the next breeding attempts (Newton 1998, p. 55). Assuming large variation of territory quality, long life span, and low costs of changing the territory's location (Switzer 1993), for most young males settling in a given area, there should be future prospects of getting a territory better than the one currently occupied. Males can obtain better territories in the next breeding season, when they are older and more experienced. Such territory shifting should continue from year to year until the male occupies the best place. Then, because there is no reason to change again, that male should stay there for the rest of his life.

There are reports confirming this simple scenario. Queuing for territory positions has been proposed as a mechanism operating in lekking species, whose males compete to move their territories toward the lek center (Kokko et al. 1998). By taking over adjacent territories, territorial lesser sheathbills Chionis minor queue toward territories with seabird colonies, where they attain the highest breeding success (Bried and Jouventin 1998). In males of the great reed warbler Acrocephalus arundinaceus, Bensch and Hasselquist (1991) reported territory infidelity, with next-year territories having higher reproductive success. Oystercatchers Himantopus ostralegus have a specific 
system of territorial "careers" (Ens et al. 1995). In a tropical species, the dusky antbird Cercomacra tyrannina, with year-round territories and pair bonds, males use any occasion to switch to a better territory and mate (Morton et al. 2000). In painted buntings Passerina ciris, males even engage in aggressive contests to take over the best territories from their previous-year owners (Lanyon and Thompson 1986).

Apart from these clear mechanisms, where the role of an environmental cue is played by an important resource (e.g., distance to lek center, seabird colony, salt marsh/mudflat edge, etc.), the commonest factor influencing the settlement decision for many birds seems to be previous experience of breeding failure, influencing site fidelity (e.g., Beheler et al. 2003; Forero et al. 1999; Gill and Stutchbury 2006; Hopp et al. 1999; Shields 1984). A simple behavioral rule regulating the occurrence of site/territory fidelity has been proposed: if breeding in a given territory was successful, the male should retain it next year; if not, the male should move elsewhere (e.g., Haas 1998; Hoover 2003 and citations therein).

In some populations, however, site fidelity of males leads to evidently maladaptive settlement of territories (e.g., Wiens et al. 1986), when males are faithful to areas that have lost their previous value. Some studies report adult birds apparently refraining from moving to better available territories (e.g., Krebs 1971). Such maladaptive settlement is suggested to be a result of decoupling of environmental and fitness cues, so that individuals are attracted to areas of low suitability (Kokko and Sutherland 2001; Misenhelter and Rotenberry 2000; Shochat et al. 2005). Such maladaptive choices would seem to imply that rigid inherited habitat preferences are the only mechanism of territory choice in those species. A question to consider in relation to avoidance of the consequences of an ecological trap (Kokko and Sutherland 2001) is the relative importance of inherited preferences and individual experience: if an individual settles in a territory whose environmental cues indicate low quality but then breeds there successfully, will that be enough to keep it there for the next season? Or, if an individual settles in an apparently good territory but then breeding is unsuccessful, will it return to that territory next year?

The aim of this study was to determine the factors affecting territory choice in sedge warbler males in consecutive years of their breeding careers. This small migratory warbler is especially interesting because areas of tall wetland vegetation (mainly common reed Phragmites australis and cattail Typha latifolia) are its preferred environmental feature, a feature positively related to fitness and thus offering an excellent indicator of habitat quality (Zając et al. 2006, 2008a). There are two possible mechanisms of territory choice, which can operate separately or in concert:
1. Because tall wetland vegetation is a reliable environmental cue of high territory quality, it may be the cue used by sedge warblers during territory selection; each male should shift his territory in order to increase the proportion of tall wetland vegetation in the territories he holds during his breeding career.

2. Because in many species, breeding failure seems to prompt a territory shift, then in the sedge warbler, the decision on a new location to hold should depend on the breeding result in the previous season.

The relative importance of the two mechanisms can be determined by testing the following predictions:

1. Next-season arrival date-because in migratory species, the territories are unoccupied at the beginning of the season, and the earliest arrivers occupy the best ones, then:

(a) The male's ability to improve territory quality should depend on his arrival date - the earlier the arrival, the larger the area of preferred vegetation in his territory.

(b) If the previous year's territory quality prompts a shift (and improvement) of territory in the next season, then the worse the territory the male had in the previous season, the earlier should be his arrival in the next season. However, if failure prompts a territory shift (and improvement) in the next season, then a male whose last-year breeding attempts failed should return earlier than successful ones do.

2. Distance of territory shift-assuming that the distance of the territory shift should reflect the strength of the negatives in the territory occupied previously, the strength of the relationship between the distance the territory was shifted and the two factors considered responsible for the decision to shift territory (poor quality in terms of tall wetland vegetation or breeding failure) should reflect their relative importance in the males' decisions.

3. Territory quality improvement - if improving territory quality (measured in terms of vegetation) is the only driver of territory shifting, there should be no relationship between the rate of increase of territory quality and the previous season's failure.

4. Fitness improvement-the interseasonal distance of territory shift or the magnitude of vegetation change should differ between males according to the improvement or decline in their breeding success between consecutive seasons - the distance should increase after the previous season's failure, whereas tall wetland vegetation cover should decrease if the male's breeding success declines and should increase or stay the same if it improves. 


\section{Materials and methods}

\section{Study area}

The study was conducted between 1996 and 2008 in a large area of natural wetlands in the Nida River valley, southern Poland $\left(20^{\circ} 28^{\prime}-20^{\circ} 32^{\prime}\right.$ E, $\left.50^{\circ} 33^{\prime}-50^{\circ} 35^{\prime} \mathrm{N}\right)$. The study plot comprised two large wetland areas separated by large areas of pasture and meadows, all of which lie between two side arms of the river. The first wetland, labeled HT, covers ca 36.3 ha of flat terrain between two side arms of the river, with many old river beds and areas of standing water of various size and depth, concentrated in the wet center and dispersed at the drier edges of the plot. Most of the wetland is covered by extensive areas of sedge (ca $30 \%$ of the area, mainly Carex elata) and by meadow communities in drier areas (53\%). Small patches of inundated land are fragmented and dispersed in the plot, overgrown mainly with cattail (5.6\%), sweetgrass Glyceria maxima (8.5\%), and with several small and dispersed patches of common reed $(0.4 \%)$. The second wetland, labeled HM, covers ca 13.5 ha and is located ca $1 \mathrm{~km}$ north of HT. Wetland HM vegetation and relief are much less diversified: a flat area overgrown with a few extensive patches of common reed (18\%), surrounded by large areas of sedge (67\%, mainly C. elata), less sweetgrass $(4 \%)$, and reed canary grass Phalaris arundinacea $(2.5 \%)$. The area surrounding the wetlands is generally open landscape, with extensive meadows and pasture, very small and dispersed water bodies, and old roads, with some trees planted along roadsides. More details are given by Bielański et al. (2005) and Zając et al. (2006, 2008a).

Before the start of each breeding season, the land cover of the study area was mapped to 1-m accuracy with a GPS receiver and classified by the main vegetation types (meadow, sedge, sweetgrass, cattail, common reed, alder woods) and open water. The boundaries and attributes of the subdivisions were imported to Geographic Information System software (ArcGIS), with which a detailed digital map of the study area was made.

\section{Field protocol}

The majority of male sedge warblers arrive from winter quarters in late April and early May, with some arriving throughout the breeding season until July. Any males appearing were promptly mist netted and ringed with a numbered aluminum ring and a unique combination of three color rings (females were caught after egg laying). We monitored the breeding behavior and reproductive success of all marked sedge warblers throughout each breeding season. Detailed surveys of the study area were made at least three times a week; the positions of all color-ringed individuals were plotted on a map together with their behaviors recorded at those times. Sedge warblers occupied mainly the wetlands of the two study areas; single males rarely occupied small water bodies dispersed around the main wetlands.

A male was considered mated mainly when it was observed guarding a female, additionally confirmed by observations of young being fed, a nest being built, or a completed nest in its territory. Nests were found by observing the behavior of the parents (mainly females carrying material for nest construction). The nests were carefully inspected around the expected hatching date in order to record clutch size and hatching date. On the eighth day after hatching, nestlings were ringed with a numbered aluminum ring. If there were no clear indications of later failure, then the nest was regarded as successful. In the following year, all individuals were caught; in this way, the recruits were recognized by the numbered rings put on them in the nest, and the number of recruits was recorded for each breeding male.

There are no reliable traits for determining age in the adult sedge warbler in the field. In this work, we were interested in males recorded during at least two breeding seasons in consecutive years of their breeding career. Assuming that every year, most of our non-ringed breeding birds are yearlings (Newton 1992), birds recorded in the first, second, and third (etc.) consecutive seasons in our study area should be in their first, second, and third (etc.) breeding seasons; however, some of them might be late immigrants, so we assume that the consecutive seasons reflect their experience within the area rather than their absolute age.

Individual territory characteristics and distance of territory shift

The data collected in the field were entered into the GIS system. The spatial data were analyzed in detail with ArcGIS software. All the males breeding in the whole study area were analyzed together. We did not do two separate analyses for the two different wetlands as we did in other published work, because some of the analyzed males changed study plots between seasons or bred in small reedbeds situated between the study plots.

In order to study the vegetation characteristics in consecutive years, it was necessary to sample the vegetation in the males' territories in a repeatable and comparable way for different individuals and different places, and also between years for the same individuals. The composition of the vegetation in the territory was sampled in circular spatial buffers $30 \mathrm{~m}$ in radius around all of the males' songposts on the first day after arrival, delimited on the digital map. The sampled area roughly matched the male's 
territory and its immediate surroundings. Then, the area covered by the main vegetation types was measured for each buffer and averaged for all buffers of the given male. For further analyses of territory quality, we used the pooled area of two vegetation types constituting distinctive types of tall wetland vegetation cover (common reed and cattail), because they were preferred during settlement by sedge warbler males (Zając et al. 2006, 2008a). This procedure gave an "averaged" sample of vegetation in an area occupied by a single male, describing the value of the male's territory in terms of the proportion of preferred vegetation in it (for details of this method, see Zając et al. 2006).

To estimate the distance of territory shifts between years, for each analyzed male, the midpoint of all songposts on the first day after arrival was estimated for each season. Later on, the various territorial activities of the male can influence territory location and its boundaries (Zając et al. 2008b). Then, the distance between midpoints was measured (in meters) in consecutive years (Fig. 1). Distances were $\log 10$ transformed to achieve normality.

Throughout this study, territories were set up at many of the same sites within the study area year after year. Such sites were repeatedly occupied in different years by different males. To delimit all potential sites present within the study area, we used the locations of territories and nests in years of the highest population number during the whole period of the study $(1996,2001,2002)$. Clusters of nests and overlapping territories occurring in the same places throughout the whole of the study period were defined as sites (for details of the method, see Zajacc et al. 2008a). Site occupancy was determined as the number of first breeding attempts recorded throughout the study period at a given site. For analyses in which occupancy was a predictor variable, the number of males was lower than in other analyses (five individuals in the males' first season and four individuals in their third season). This is because, for some males whose territories were set up outside the study area, we could assess the landcover characteristics, but we did not know the number of breeding attempts that had been made in these places before (for similar reasons, we do not use data for one male in the third season in the analysis of arrival date and vegetation; $n=39$ in that analysis).

\section{Statistical analysis}

We analyzed the data in separate age classes in order to compare the same individuals in successive age classes, eliminating individuals that did not survive to the next age class; another reason for this was to visualize differences between age classes, which could be obscured by too general or too complicated a model.

In order to compare the males' arrival dates between consecutive seasons, we used the standardized date (i.e., the arrival date of the first male in a given season was coded 0 , and the dates were counted continuously onward).

The difference in arrival dates between two consecutive seasons (prediction 1b) was analyzed as a response variable by general linear model (GLM) multivariate analysis of repeated measures in relation to the previous season's male

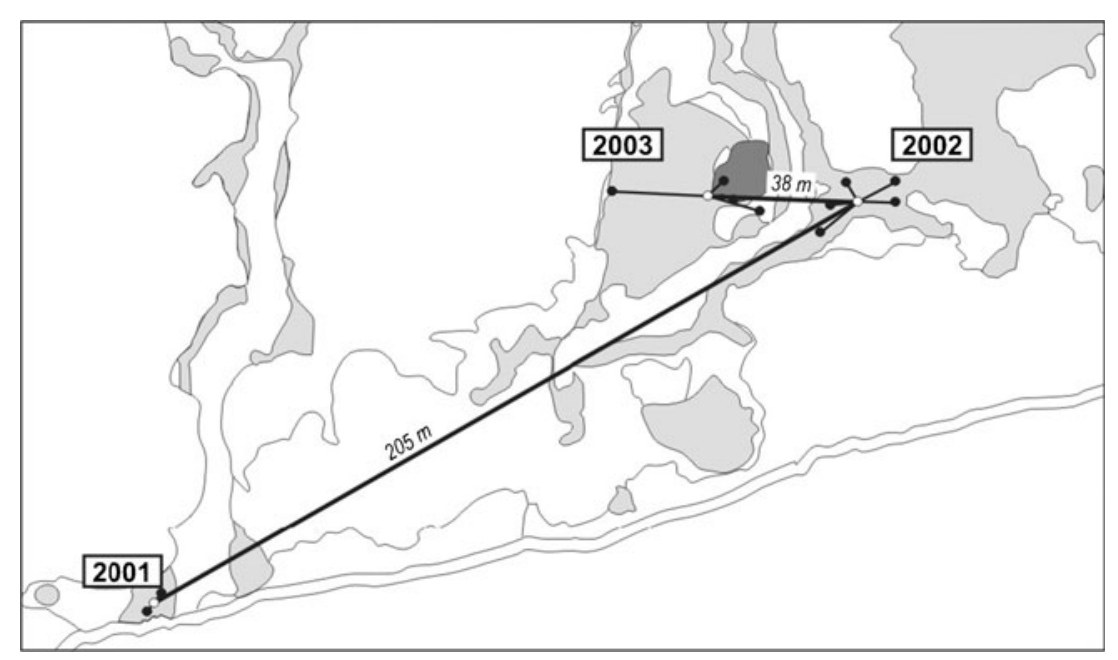

Fig. 1 Example of measurement of consecutive territory shifts of a sedge warbler male. In 2001, the first territory of the male coded OWO was occupied in the most peripheral western part of study plot HT. It achieved mating, but nesting failed. In the next year, it was observed close to a territory that is occupied very early in each breeding season. It mated and raised a successful brood. In 2003, it occupied this best site (with a common reed patch), where it mated and probably lost the clutch in an early stage of incubation. Every year, all its records during the first day after arrival were plotted on the GIS map, then their midpoint was found, and the distances between midpoints in consecutive seasons were measured. Gray patches cattail, dark gray common reed, black dots songposts during the first day after settlement, open dots midpoints of the songposts in consecutive seasons 
breeding success and tall wetland vegetation cover in its territory at that time, as predictor variables. Breeding success was analyzed separately for mating success (binary variable: 0 , no success; 1 , success) and for nesting success ( 0 , no fledglings; 1 , at least one fledgling raised) in the preceding season, as well as in relation to tall wetland vegetation cover in its territory in the preceding season. We used GLM models of repeated measures also to assess the influence of mating/nesting success and previous-year territory quality (in terms of occupancy) on the change in tall wetland vegetation cover in a male's territory between consecutive breeding seasons. In order to avoid using the same environmental feature as response and explanatory variable, the quality of the previous-season territory was expressed in terms of territory occupancy (Sergio and Newton 2003; Zajac et al. 2008a), that is, the number of years during which a given territory was occupied by a breeding male.

We also used GLM models to analyze the relationships between distance of territory shift (response variable) and predictor variables including (1) previous-season male territory quality in terms of vegetation, (2) failure/success impact (binary variable: 0 , no success; 1 , success), and (3) change of arrival date between consecutive seasons.

The distance of territory shift between consecutive seasons and the change in vegetation cover in territories were compared between categories of the change in the males' success between consecutive breeding seasons. The fitness change could be negative (when a male was successful in a given year and unsuccessful in the next one, 1-0), positive (no success followed by a successful season, 0-1), or with no change, that is, with both years unsuccessful (0-0) or successful (1-1). Three fitness components were recognized: (1) mating success, analyzed for all males; (2) nesting success, analyzed only for mated males; and (3) the recruitment success of a male's offspring, analyzed for males that fledged at least one young in both compared seasons.

All analyses were done with JMP IN (release 5.1.2., SAS Institute 2004) and Statistica (release 8).

\section{Results}

\section{Background information}

During the 13 years of the study, the first males in spring arrived at the study area on 27 April, on average (SD= 4.4 days), and $53.7 \%$ of all males $(n=598)$ arrived within 10 days of the first male arrival. About $41 \%$ of the males failed to mate (see Zajac et al. 2006 for details), 33\% of all males raised only one brood per season, $1.7 \%$ of all males raised a second brood with the same female, and only $2.3 \%$ of all males mated polygynously. Clutch size showed little variation, with a mean of 5.2 eggs $(\mathrm{SD}=0.76, n=182)$, and similar fledging success (mean, 4.81 fledglings; $\mathrm{SD}=0.97$; $n=214$ ). Only $19 \%$ of the males with nesting success raised any recruits (mean, 1.15 recruits/male; $\mathrm{SD}=0.43$ ). The number of males in the study area did not show directional tendencies between seasons. Of the 598 males ringed during the study period in their first breeding season, 132 (22\%) males returned to the study area for their second season, $40(30 \%)$ continued to return through the third breeding season, $14(11 \%)$ through the fourth, and only one male returned in the fifth breeding season. During the whole study period, 18 males (14\% of 132 analyzed) moved between the main wetlands or adjacent areas.

\section{Lifetime patterns of features related to territory shift}

During their consecutive breeding seasons, males improved the quality (vegetation) of their territories, but the between-season difference for the same male was significant only between the first and second breeding seasons (Fig. 2a), though the mean cover of tall wetland vegetation did trend upward in the next seasons (up to 0.49 ). The pattern was very similar for territory quality measured as their occupancy (Fig. 2b), although the uptrend disappeared in the two oldest age classes.

The settlement dates of males arriving from winter quarters were progressively earlier in consecutive seasons of the same males (Fig. 2c), but again, the significant differences were restricted to the first and second seasons; later, the differences decreased and ultimately disappeared. The territory shift distances were not related significantly to the males' age, although they also tended to shorten from season to season (Fig. 2d).

Clutch size increased significantly until the third season of male life, and then, the number of eggs declined, though the differences for late age classes were not statistically significant (Fig. 2e). Given the increase in clutch size across consecutive seasons for a given male, it is not surprising that the pattern was similar although not significant for fledgling number (Fig. 2e) and for recruits (Fig. 2f).

The proportion of males ending the breeding season without nesting success (mainly due to predation) was fairly consistent in consecutive seasons of the males' breeding careers. In their first breeding season, $35 \%$ of mated males failed to achieve breeding success; in the second, $36 \%$; in the third, also $36 \%$; and in the fourth, 27\%. Males whose nests were destroyed did not differ from successful males in terms of arrival date (mean arrival date $11.7(\mathrm{SD}=15.5)$ for successful and 12.3 $(\mathrm{SD}=12.7)$ for unsuccessful males; $\left.t_{346}=0.68, p=0.49\right)$, nor in terms of tall wetland vegetation cover of their territories (mean proportion of tall vegetation cover $0.13(\mathrm{SD}=0.068)$ for successful and $0.13(\mathrm{SD}=0.070)$ for unsuccessful males; $t_{346}=0.99, p=0.32$ ). 
Fig. 2 Differences between consecutive seasons of sedge warbler male breeding careers in: a tall wetland vegetation cover within territories, $\mathbf{b}$ occupancy of territory, $\mathbf{c}$ arrival date, $\mathbf{d}$ distance between territories, $\mathbf{e}$ nesting success (number of eggs laid, black boxes; number of fledged young, gray boxes) with the respective $t$ test statistics shown for number of eggs laid (upper part) and for number of fledged young (lower part), $\mathbf{f}$ number of recruits. All $t$ tests are for matched pairs
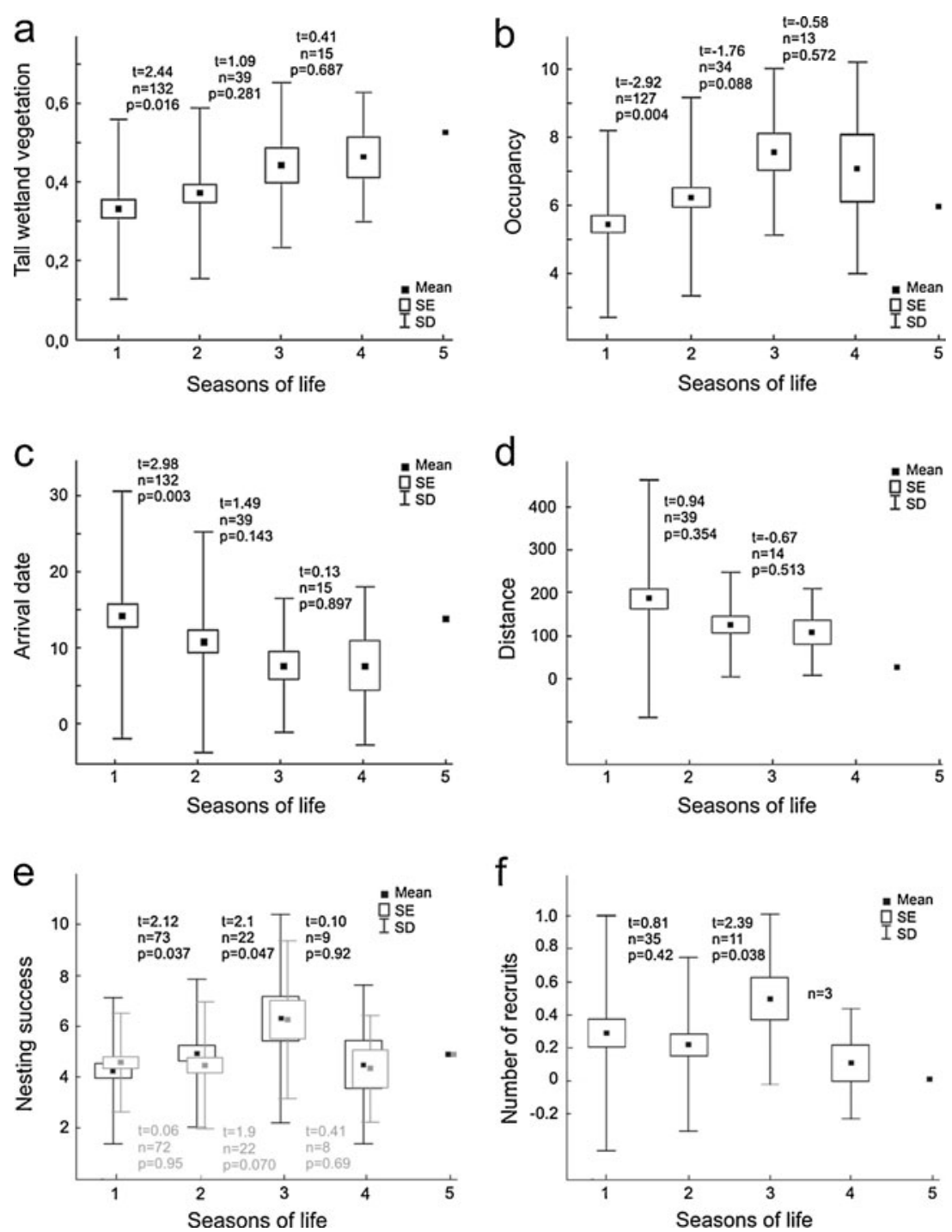

\section{Prediction tests}

\section{Prediction 1a-territory improvement a result of earlier arrival}

Earlier-settling males occupied places with a higher proportion of tall wetland vegetation $(r=-0.34, n=439$, $p<0.0001$; to avoid pseudoreplication, only males recorded for the first time in the study plot (naive males) were analyzed). Among males that returned for more than one breeding season, earlier arrival in the next season was associated with increased area of tall wetland vegetation in their territories; arrival later in the season was associated with decreased cover of that vegetation (second vs first season, $r=-0.18, n=132, p=0.040$, Fig. $3 \mathrm{a}$; third vs second season, $r=-0.53, n=39, p=0.001$, Fig. $3 \mathrm{~b}$; fourth vs third, $r=-0.20, n=15, p=0.48$ ).
Prediction 1b-arrival date and previous-season factors

GLM multivariate analysis of repeated measures showed that the same males' arrival dates differed significantly between the first and second and between the second and third seasons. Previous-year vegetation cover of a territory was significantly related to the change in arrival date between the first and second and also between the second and third seasons (Table 1). Mating success was significantly related to the change in arrival date between the second and third seasons only.

The same analysis repeated only for mated males with nesting success as predictor variable also showed a significant change of arrival date between the first and second seasons (change of arrival date between the second and third seasons was close to significance), but the change in arrival date interacted significantly only with the previous year's vegetation cover (second season, Table 1). 

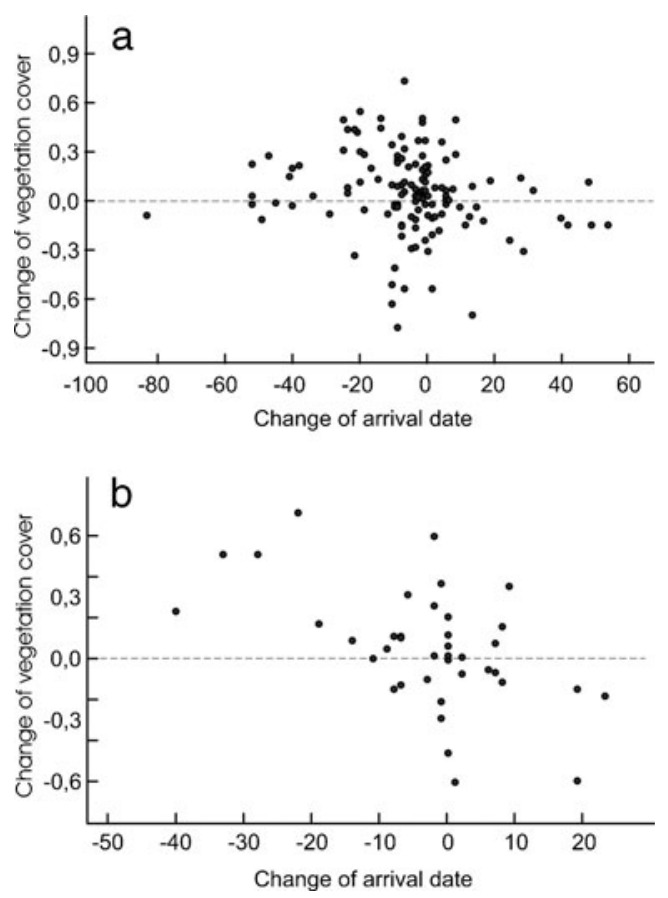

Fig. 3 Relationship between the change of males' arrival dates between seasons and the corresponding change in the proportion of tall wetland vegetation at their sites between seasons (a first and second seasons, $\mathbf{b}$ second and third seasons)

Underlying relationships and data The arrival date in consecutive seasons showed a significant positive correlation with the previous season's territory quality in the group of males analyzed for mating success in the two younger classes of males - the worse the first territory, the earlier the arrival in the next season (Table 1).

Most of the males arrived earlier the next year than in the preceding year (Table 1), but the change in arrival date did not differ significantly in relation to breeding success attained the year before, except for a significant difference in the males' third breeding season, when unmated males returned earlier than the year before whereas mated males showed almost no change.

\section{Prediction 2-distance of territory shift}

The GLM models (Table 2) show significant effects of vegetation cover in the previous-year territory on the distance of territory shift between the first and second seasons. This relationship was negative and significant both for all analyzed males and for mated males. The effect of previous-year mating or nesting success on territory shift was not significant.

Underlying relationships and data The distance of territory shift between the first and second breeding seasons was negatively correlated with vegetation cover in the first season only in the analysis of all males (Table 2). The average distance between a male's successive territories in the first and second breeding seasons differed very significantly with regard to the influence of previous-year success.

\section{Prediction 3-territory quality improvement}

The GLM models of repeated measures (Table 3) confirmed a significant change of tall wetland vegetation cover between successive years of the males' breeding career. There was significant interaction between change in vegetation and site occupancy in the first year in the analysis of all males. In neither case did mating or nesting success show any significant relationship to improvement of territory quality in consecutive seasons.

\section{Prediction 4-fitness improvement}

The distances of the territory shift between the first and second seasons did not differ significantly between mating success categories (one-way ANOVA: $F_{3,128}=2.15, p=0.098$; Fig. 4a), nor between nesting success categories (one-way ANOVA: $F_{3,128}=2.31, p=0.080$; Fig. $4 \mathrm{~b}$ ). For recruitment success, the variance of shift distances was unusually high in males that were unsuccessful in the first season and improved their fitness in the second season (category 0-1; Bartlett test: chisquare $=14.0, d f=3, p=0.002$; Fig. $4 \mathrm{c}$ ), and territory shift distance differed significantly (Kruskal-Wallis test: $H_{3,35}=$ 9.22, $p=0.026$; Fig. 4c). Post hoc pairwise comparisons indicated that males that failed to produce recruits in both their first and second seasons $(0-0)$ had longer shift distances than males successful in both seasons (1-1), although the difference is still nonsignificant $(p=0.059)$.

The change of territory vegetation cover between the first and second seasons did not differ significantly between mating success categories (one-way ANOVA: $F_{3,128}=0.07$, $p=0.975$; Fig. $4 \mathrm{~d}$ ), nor between nesting success categories (one-way ANOVA: $F_{3,128}=0.49, p=0.688$; Fig. $4 \mathrm{e}$ ). However, recruitment success categories differed significantly in the change of tall wetland vegetation cover (one-way ANOVA: $F_{3,32}=5.06, p=0.006$; Fig. $4 \mathrm{f}$ ). The LSD test indicated that males whose success decreased from the first to second seasons (1-0) also significantly decreased territory quality more than those producing no recruits at all in the first and second seasons $(0-0, p=0.0007)$. It should be noted that the territory quality of males with declining success was on average 0.28 poorer than the year before, while territory quality did not change more than 0.10 for the remaining categories of breeding success change (Fig. 4f).

The data for fitness change between the second and third seasons show that the distance of territory shifts for those seasons did not differ significantly between mating success categories (one-way ANOVA: $F_{3,36}=0.57, p=0.64$ ). Among the mated males, there were no individuals whose nesting or recruitment success decreased between the second and third 
Table 1 Change of arrival date in consecutive breeding seasons of the studied sedge warbler males, analyzed by GLM multivariate analysis of repeated measures (models), with interactions of arrival date change with mating or nesting success in the preceding year and quality of their territories at that time, as measured by tall wetland vegetation cover

\begin{tabular}{|c|c|c|c|c|c|c|c|c|c|c|c|}
\hline \multirow{2}{*}{$\begin{array}{l}\text { Success } \\
\text { measure }\end{array}$} & \multirow{2}{*}{$\begin{array}{l}\text { Change } \\
\text { between } \\
\text { seasons }\end{array}$} & \multicolumn{5}{|l|}{ Models } & \multicolumn{5}{|c|}{ Underlying relationships and data } \\
\hline & & Model effects & Value & $F$ & DenDF & $p$ & $r$ & $\begin{array}{l}\text { Previous } \\
\text { year success }\end{array}$ & $\begin{array}{l}\text { Mean } \Delta \text { arrival } \\
\text { (a.) date (days) }\end{array}$ & $\mathrm{SD}(n)$ & $t$ \\
\hline \multirow{9}{*}{$\begin{array}{l}\text { Mating success } \\
\text { (all males) }\end{array}$} & \multirow[t]{3}{*}{1 st vs 2 nd } & $\Delta$ arrival date & 0.037 & 4.80 & 129 & 0.030 & & & & & \\
\hline & & Success $* \Delta$ a. date & 0.001 & 0.15 & 129 & 0.701 & & $\begin{array}{l}0 \\
1\end{array}$ & $\begin{array}{l}-4.9 \\
-5.2\end{array}$ & $\begin{array}{l}21.8(29) \\
19.3(103)\end{array}$ & 0.08 \\
\hline & & $\mathrm{TWV}^{*} \Delta$ a. date & 0.034 & 4.34 & 129 & 0.039 & $0.18^{*}$ & & & $(132)$ & \\
\hline & \multirow[t]{3}{*}{ 2nd vs 3 rd } & $\Delta$ arrival date & 0.580 & 20.88 & 36 & $<0.0001$ & & & & & \\
\hline & & Success $* \Delta$ a. date & 0.125 & 4.48 & 36 & 0.041 & & $\begin{array}{l}0 \\
1\end{array}$ & $\begin{array}{r}-10.0 \\
-0.4\end{array}$ & $\begin{array}{l}16.0(11) \\
10.5(28)\end{array}$ & $2.18^{*}$ \\
\hline & & $\mathrm{TWV}^{*} \Delta$ a. date & 0.336 & 12.09 & 36 & 0.001 & $0.50^{* *}$ & & & $(39)$ & \\
\hline & \multirow[t]{3}{*}{3 rd vs 4 th } & $\Delta$ arrival date & 0.021 & 0.25 & 12 & 0.625 & & & & & \\
\hline & & Success $* \Delta$ a. date & 0.033 & 0.39 & 12 & 0.541 & & 0 & -2.7 & $15.3(3)$ & 0.57 \\
\hline & & $\mathrm{TWV}^{*} \Delta$ a. date & 0.007 & 0.09 & 12 & 0.771 & 0.14 & 1 & 1.1 & $\begin{array}{r}8.82(12) \\
(15)\end{array}$ & \\
\hline \multirow{9}{*}{$\begin{array}{l}\text { Nesting success } \\
\text { (mated males } \\
\text { only) }\end{array}$} & \multirow[t]{3}{*}{1 st vs 2 nd } & $\Delta$ arrival date & 0.049 & 4.93 & 100 & 0.029 & & & & & \\
\hline & & Success $* \Delta$ a. date & 0.001 & 0.14 & 100 & 0.714 & & $\begin{array}{l}0 \\
1\end{array}$ & $\begin{array}{l}-6.6 \\
-4.4\end{array}$ & $\begin{array}{l}19.6(36) \\
19.3(67)\end{array}$ & 0.54 \\
\hline & & $\mathrm{TWV}^{*} \Delta$ a. date & 0.013 & 1.27 & 100 & 0.262 & 0.12 & & & (103) & \\
\hline & \multirow[t]{3}{*}{2 nd vs 3 rd } & $\Delta$ arrival date & 0.118 & 2.95 & 25 & 0.098 & & & & & \\
\hline & & Success $* \Delta$ a. date & 0.011 & 0.28 & 25 & 0.602 & & $\begin{array}{l}0 \\
1\end{array}$ & $\begin{array}{l}0.22 \\
0.47\end{array}$ & $\begin{array}{l}15.0(9) \\
8.15(19)\end{array}$ & 0.06 \\
\hline & & $\mathrm{TWV}^{*} \Delta$ a. date & 0.171 & 4.26 & 25 & 0.049 & 0.37 & & & $(28)$ & \\
\hline & \multirow[t]{3}{*}{3 rd vs 4 th } & $\Delta$ arrival date & 0.026 & 0.23 & 9 & 0.641 & & & & & \\
\hline & & Success $* \Delta$ a. date & 0.417 & 3.76 & 9 & 0.084 & & $\begin{array}{l}0 \\
1\end{array}$ & $\begin{array}{c}5 \\
-4.4\end{array}$ & $\begin{array}{l}6.13(7) \\
9.63(5)\end{array}$ & 2.08 \\
\hline & & $\mathrm{TWV}^{*} \Delta$ a. date & 0.036 & 0.33 & 9 & 0.582 & 0.21 & & & (12) & \\
\hline
\end{tabular}

In all cases, NumDF is equal to 1 . The second section of the table (underlying relationships and data) presents the basic relationships which underlie the model: correlation coefficients $(r)$ of territory quality in the preceding year and change in arrival time of the next year, as well as the means of change in arrival date, compared separately for males without (0) or with (1) mating or nesting success

$T W V$ tall wetland vegetation, sum of cattail and reed area in a male's territory

$*-0.01<p<0.05, * *-0.01<p<0.001$

seasons. Territory shift distance did not differ between nesting success categories (one-way ANOVA: $F_{2,36}=0.85$, $p=0.44$ ), nor between recruitment success categories (oneway ANOVA for males that achieved nesting success in both years: $\left.F_{2,12}=1.29, p=0.31\right)$. Nor did the area of tall wetland vegetation within the territories differ between mating success categories (one-way ANOVA: $F_{3,36}=0.62$, $p=0.60$ ), nesting success categories (one-way ANOVA: $F_{2,36}=0.11, p=0.90$ ), or recruitment success categories (one-way ANOVA: $F_{2,12}=0.19, p=0.83$ ). For older age classes, this type of analysis was not suited because the samples were too small.

\section{Discussion}

The first two seasons of life of sedge warbler males proved crucial to the outcomes reflected in other analyzed traits: the mean area of tall wetland vegetation increased significantly between the first and second seasons, and this pattern was similar for territory occupancy, arrival date, and fitness. Similar correlations of age with different traits have been reported in other species as well (e.g., Gonzalez-Solis et al. 2004; Mauck et al. 2004; Low et al. 2007).

The match between the lifetime pattern of arrival dates and the pattern of territory improvement (vegetation and 
Table 2 Models of the relationships between the distance a sedge warbler male shifts territory between season " $t$ " and season " $t+1$ " (response variable in GLM analysis) and an explanatory binary variable describing a measure of breeding success (mating or nesting success in season "t"), the vegetation quality of season " $t$ " territory, and the change of arrival date between consecutive seasons as covariates

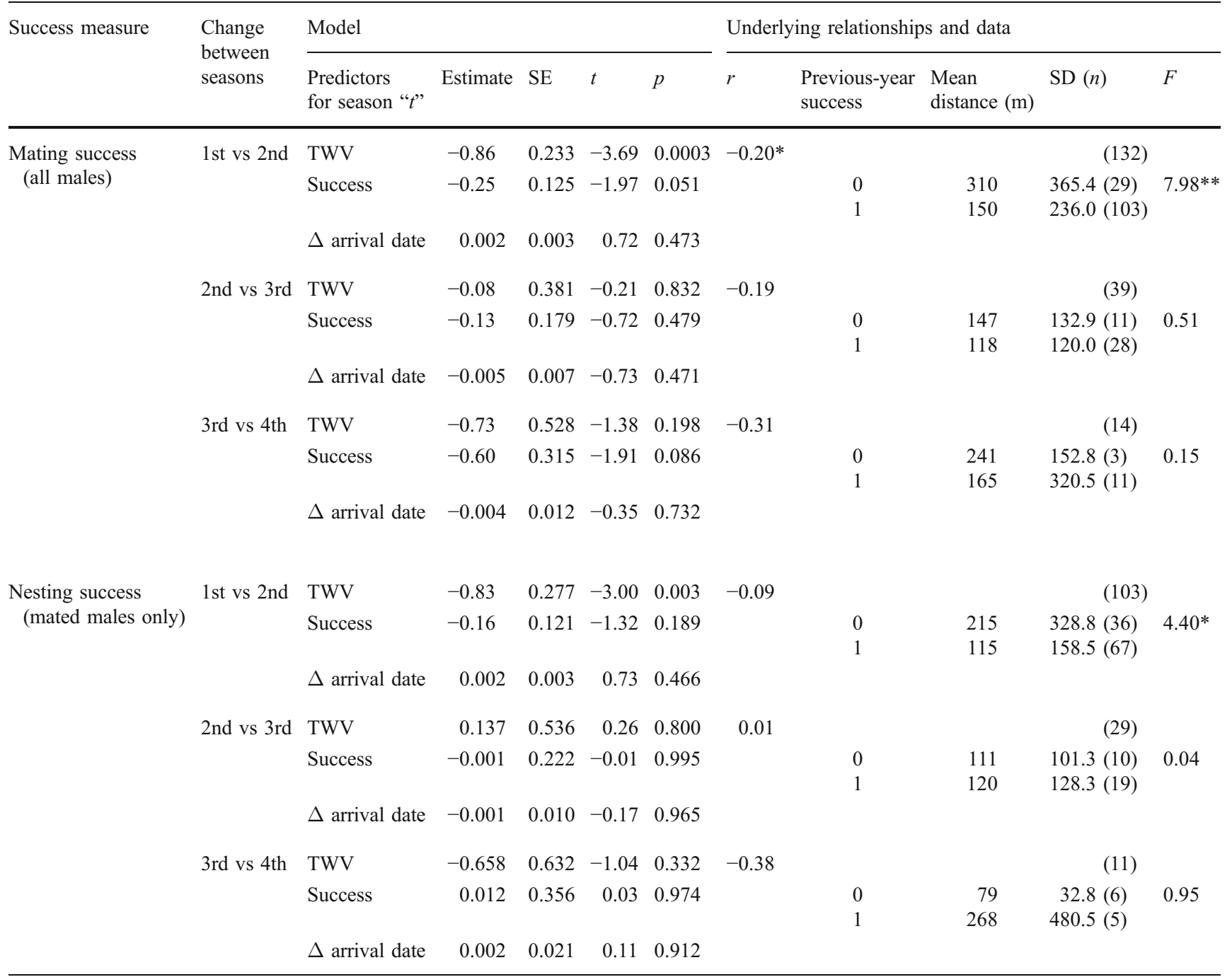

Distance and territory quality were transformed $(\log 10$ and square root, respectively) in order to approximate a normal distribution. The second section of the table (underlying relationships and data) presents the basic relationships that underlie the model: correlation coefficients $(r)$ of territory quality in the preceding year and the distance a sedge warbler male shifts territory between seasons, as well as the distance differences between males without (0) or with (1) mating or nesting success

$T W V$ tall wetland vegetation, sum of cattail and reed area in a male's territory

$*-0.01<p<0.05, * *-p=0.005$

occupancy) indicates that the improvement may be based on earlier arrival. If the quality of a male's consecutive territories increases, then the territory shift distance should decrease, because a male should have less and less chance that another territory will be better than the old one and will more frequently pick the same place. At the same time, although territory shift distances seem to decrease during a male's breeding career, their high variation and lack of statistical significance suggests that other factors are at play, such as territory shift after a season of breeding failure. This is likely the case here, because the studied population has a high level of brood predation (ca one third of broods) which is relatively stable through all age classes and is unrelated to arrival date or territory quality (Zając et al. 2008a).

It is possible, then, that territory improvement and territory shifting as a result of breeding failure act in concert. The two scenarios are likely associated with each other, because they require earlier arrival in the next season in order to find territories not yet occupied (prediction 1a). If a territorial resident's probability of defeating a newcomer depends on the duration of residence (Krebs 1982; Tobias 
Table 3 Change of territory vegetation cover between the first and second years of the breeding career of sedge warbler males, analyzed by GLM multivariate analysis of repeated measures, with interactions of territory vegetation change with mating or nesting success in the preceding year and the quality of its territory at that time as measured by territory occupancy

\begin{tabular}{|c|c|c|c|c|c|c|}
\hline Success measure & Change between seasons & Model effects & Value & $F$ & DenDF & $p$ value \\
\hline \multirow[t]{6}{*}{ Mating success (all males) } & \multirow[t]{3}{*}{1 st vs 2 nd } & $\Delta \mathrm{TWV}$ & 0.056 & 7.02 & 126 & 0.009 \\
\hline & & Mating success $* \Delta \mathrm{TWV}$ & 0.003 & 0.33 & 126 & 0.564 \\
\hline & & Site occupancy* $\Delta$ TWV & 0.072 & 9.05 & 126 & 0.003 \\
\hline & \multirow[t]{3}{*}{ 2nd vs 3 rd } & $\Delta \mathrm{TWV}$ & 0.150 & 5.10 & 34 & 0.030 \\
\hline & & Mating success* $\Delta \mathrm{TWV}$ & 0.002 & 0.06 & 34 & 0.801 \\
\hline & & Site occupancy* $\Delta$ TWV & 0.073 & 2.48 & 34 & 0.124 \\
\hline \multirow[t]{6}{*}{ Nesting success (mated males only) } & \multirow[t]{3}{*}{1 st vs 2 nd } & $\Delta \mathrm{TWV}$ & 0.084 & 8.30 & 99 & 0.005 \\
\hline & & Nesting success* $\Delta$ TWV & 0.002 & 0.22 & 99 & 0.640 \\
\hline & & Site occupancy* $\Delta$ TWV & 0.038 & 3.74 & 99 & 0.056 \\
\hline & \multirow[t]{3}{*}{ 2nd vs 3 rd } & $\Delta \mathrm{TWV}$ & 0.011 & 0.26 & 25 & 0.612 \\
\hline & & Nesting success* $\Delta$ TWV & 0.049 & 1.22 & 25 & 0.280 \\
\hline & & Site occupancy* $\Delta$ TWV & 0.045 & 1.12 & 25 & 0.299 \\
\hline
\end{tabular}

Territory quality change between the third and fourth seasons was not analyzed because the small sample size precluded a reliable analysis $N u m D F 1$ for all effects; $T W V$ tall wetland vegetation, sum of cattail and reed area in a male's territory

1997), then later-arriving males, even if older and of higher individual quality, are unable to evict a new holder from their previous-year territory (pre-emption principle: Pulliam and Danielson 1991; Bensch and Hasselquist 1991; Currie et al. 2000; but also see Lanyon and Thompson 1986). Earlier-arriving males tend to shift their territories to better
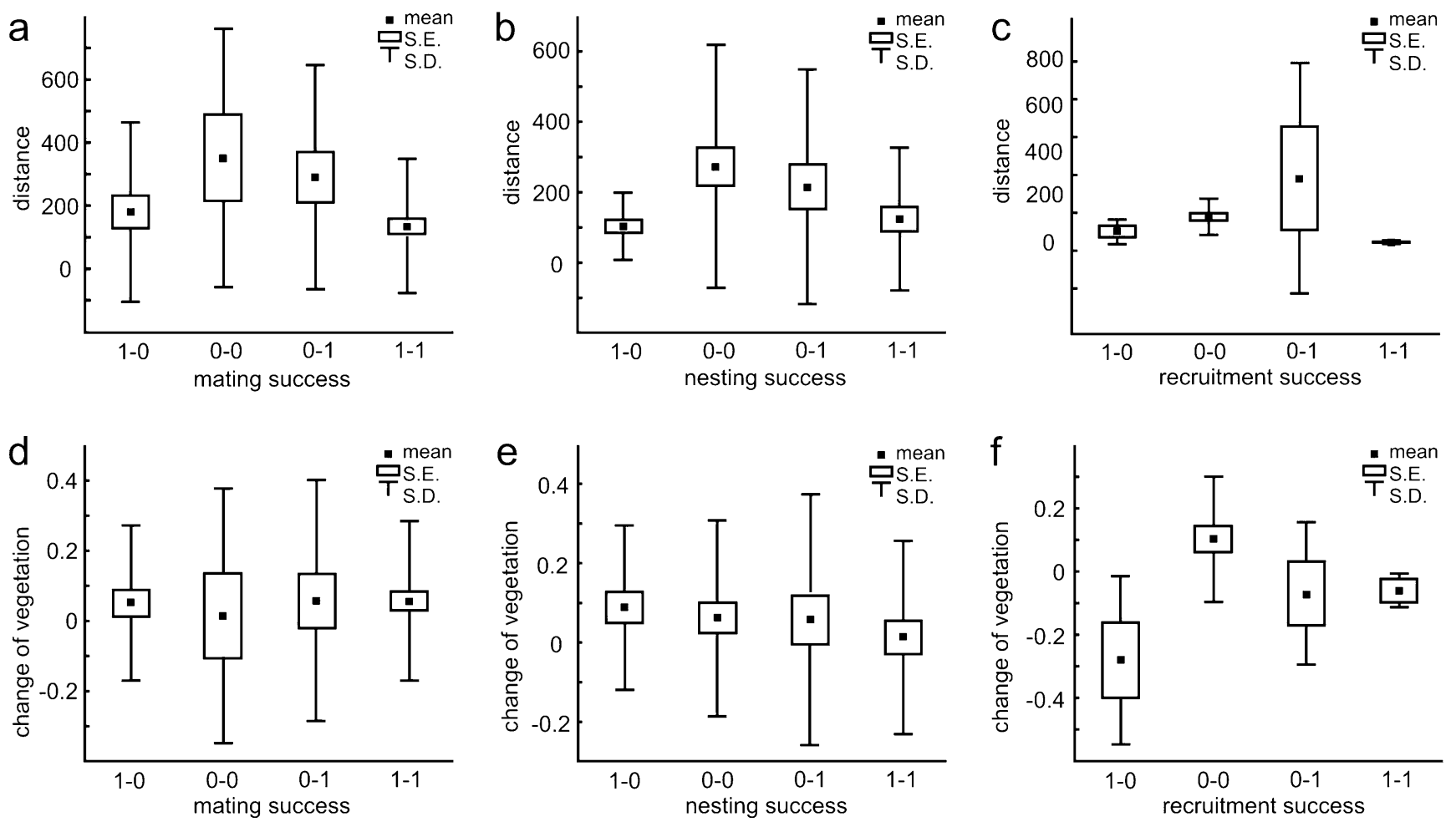

Fig. 4 Differences in territory shift distance between categories of fitness change: 1-0 males successful in the first season and unsuccessful in the second, $0-0$ males unsuccessful in both seasons, 0-1 males unsuccessful in the first season and successful in the second, 1-1 males successful in both seasons. a Shift distance differences between males differing in mating success, $\mathbf{b}$ shift distance differences between males differing in nesting success, $\mathbf{c}$ shift distance differences between males differing in recruitment success, d vegetation cover differences between males differing in mating success, e vegetation cover differences between males differing in nesting success, $\mathbf{f}$ vegetation cover differences between males differing in recruitment success 
locations, and site pre-emption may have played a role in their acquiring and successfully defending their new territories from other males arriving later.

Both territory improvement and the failure decision rule require a change in arrival date, but low territory quality clearly hastened male arrival in consecutive seasons (prediction 1b; Table 1); this was especially evident before the third season, in which breeding success seemed highest (Fig. 2e). In this age class, mating failure also seems to have influenced the arrival date (Table 1), but nesting failure did not show any relationship.

Territory shift distance, a parameter directly reflecting territory infidelity, was negatively related to previousseason territory quality, and analysis of the underlying data suggests that mating and nesting success might have some influence. Again, there were clear, significant relationships for the territory shift between the first and second seasons. Thus, prediction 2 was confirmed for both factors, although again, the relationships (especially in the summarizing model) were clearer for previous-season territory quality, while mating and nesting success had a less evident effect.

Prediction 3 states that territory quality improvement should be independent of the previous season's breeding success. This prediction was confirmed for territory quality change between the first and second seasons. Whichever index of breeding failure was used (mating or nesting), only the previous season's territory quality was related to vegetation change.

Last is the question of fitness improvement (prediction 4) because of territory change. There were virtually no relations between vegetation cover and interseasonal changes in mating or nesting success (Fig. 4d-f). Nor were there any significant differences in territory shift distance between categories of interseasonal change in mating or nesting success, although both Fig. $4 \mathrm{a}-\mathrm{c}$ and a simple comparison of distance in relation to success categories (Table 2) indicate that previousseason failure increased the territory shift distance. For recruitment, successful males that decreased the area of preferred vegetation in the next season became unsuccessful. Males that were successful in both compared seasons showed no apparent territory shift; all other fitness change categories were associated with shifts at longer distances. Males that improved their fitness (0-1) showed the greatest variation of distance, but that result was from a small sample.

The analyzed data imply that arrival date and territory quality are the main factors influencing the settlement decisions of males. Those that arrive earlier, having free access to a large number of territories, can choose the best of them, with more tall wetland vegetation cover. Those that occupied really poor territories in the first season were the latecomers; if they come earlier next year, even accidentally, they automatically improve their territory quality and show a significant positive change in vegetation cover as compared with the poor territory of the previous year. Breeding failure also seems to advance the arrival date and increase the shift distance, but this relationship is clear only for the mating episode; nesting success did not show any significant relationship if controlled for territory quality. The lack of influence of nesting failure can be explained by low variation of clutch size and fledgling number (Król et al. 2002). Variation caused by predation is also small: males do lose breeding attempts, but over half of them raise replacement broods (Zajacc 2010).

In the sedge warbler, breeding success can be much more diversified by mating: many males have no success due to mating failure, many raise only one brood, and some of them can double their success if they mate polygynously or have a second brood. Success can even be tripled if a male mating polygynously also has a second brood. If the area of tall wetland vegetation influences mating in this species (Zajacc et al. 2006), then the advantages of territory allowing successful mating can easily compensate any setbacks caused by nesting failure. If $75 \%$ of the territories do not guarantee any recruitment (Zajac et al. 2008a), then predation generating a 30\% risk of season failure (15\% if replaced broods are taken into account) seems much less important than the right choice of territory.

Of course, this mechanism does not necessarily operate in all species and may even be the exception. The sedge warbler is well known for its very strong sexual selection (Buchanan and Catchpole 1997; Marshall et al. 2003); in other species, where selection related to mating and recruitment may not operate so strongly, the experience of breeding failure may be much more important. This may be especially true in species with large clutch size and inhabiting nest boxes (e.g., Parus sp.), where predators can repeatedly visit the same nest holes or nest boxes (Sonerud 1985, 1993; Nilsson et al. 1991; Sorace et al. 2004; see also Wesołowski 2006). Facing so high a probability of repeated failure, even undirected escape from an endangered area and random selection of the next territory can increase the success of future breeding attempts.

Having a clear environmental signal that reflects territory quality, a male can choose the best territory from the available options. Such a mechanism seems to be widespread, although it can be based on cues other than vegetation, such as conspecific attraction (Stamps 1988, 1991; Muller et al. 1997) or public information (Valone and Templeton 2002; Doligez et al. 2002, 2004). This would imply the need for reconsideration of the problem: if searching for a better territory is a widespread behavior, then it is not nesting failure which drives a random shift of territory; rather, it is success which puts a halt to further searches for better territory, whereas nesting failure gives a signal to resume the effort at another starting point. In such an approach, there would be no need for territory "fidelity" and "infidelity" but one general mechanism of territory search, which is stopped after reaching some threshold value of the cues. The search is resumed if failure indicates that the threshold value for the nesting success cue was not actually reached. The relative influence of this cue in relation to others 
would then depend on species biology: for example, it would be small in species with significant variation of mating success determined by territory quality or large in the case of high variation of the parents' fitness determined by only nesting success. Such an approach provides a single framework for many factors determining settlement decisions (habitat cues, conspecific attraction, public information, etc.) and the failure decision rule, confirmed in so many species.

There are many studies demonstrating the "win-stay/ lose-shift" decision rule, but some of them are in line with the approach proposed for the sedge warbler; for example, Hoover (2003) experimentally demonstrated the influence of not only nesting failure but also increased success on fidelity, the latter supporting the approach offered here. Some studies seem to confirm the operation of a mixed strategy of territory shift. In bobolinks Dolichonyx oryzivorus on high-quality study plots, individuals returned in the next season at similar rates regardless of their previousyear nesting success. At poor-quality plots, the majority of unsuccessful individuals did not return, and some of them were found in other areas of higher habitat quality (Bollinger and Gavin 1989). Dispersal of Tengmalm's owl Aegolius funereus was not influenced by nesting success but was related to food availability: a declining phase in the vole population significantly increased the distance of the owls' dispersal (Korpimäki 1993). While not directly addressing the problem of territory shift, Petit and Petit's (1996) study of prothonotary warblers Protonotaria citrea clearly highlights the same mechanism of territory quality advancement in males moving from poor dry territories to good-quality sites in flooded areas. The great reed warbler is another species whose individuals have been reported to move to higher-quality territories in wetland habitat similar to that occupied by sedge warblers (Bensch and Hasselquist 1991), and the males' ability to improve their territory quality was found to depend on the arrival date. Some experimental attempts to stimulate dispersal by artificially reducing habitat quality have yielded equivocal results (e.g., Beletsky and Orians 1994; Howlett and Stutchbury 2003). In chipping sparrows Spizella passerina, Ortega et al. (2006) documented a kind of natural experiment in which an invasion of knapweed Centaurea maculosa caused deterioration of habitat quality, affecting the site fidelity of adults. The return rate of males in poor knapweed habitat was significantly lower than in highquality native habitat, and the distance of between-season shifts of territory was longer in the poor habitat.

The operation of a rigid behavioral mechanism of territory selection, such as a preference for tall wetland vegetation, would easily explain the existence of ecological traps. Birds relying on an environmental cue that has recently become decoupled from fitness may be unable to recognize the fitness consequences because their behavior is shaped by long-term factors (reviewed in Kokko and
Sutherland 2001; Robertson and Hutto 2006). On the other hand, males may have the ability to use different or additional cues. The decoupling would result in very severe selection pressure against the cue, causing rapid adaptation to other cues. Experimental manipulation of the most important habitat factors (area of tall wetland vegetation within the males' sites) and fitness components (female availability, predation) would allow an assessment of the vulnerability of male sedge warblers to an ecological trap.

Acknowledgments We are grateful to all those who took part in the field work and, in particular, to Aleksandra Biedrzycka, Kuba Janik, Wiesław Król, and Bartosz Pirga. Paweł Adamski, Paweł Olejniczak, and two anonymous reviewers provided invaluable suggestions on early versions of the manuscript. Michael Jacobs helped edit the paper. We appreciate the improvements in English usage made by Chan Robbins through the Association of Field Ornithologists' program of editorial assistance. This study was funded by grants from the Polish State Committee for Scientific Research, nos. 6P04F06412, 6P04F02320, and 2P04F06130.

Open Access This article is distributed under the terms of the Creative Commons Attribution Noncommercial License which permits any noncommercial use, distribution, and reproduction in any medium, provided the original author(s) and source are credited.

\section{References}

Beheler AS, Rhodes OE Jr, Weeks HP Jr (2003) Breeding site and mate fidelity in eastern phoebes (Sayornis phoebe) in Indiana. Auk 120:990-999

Beletsky LD, Orians GH (1994) Site fidelity and territorial movements of males in rapidly declining population of yellow-headed blackbirds. Behav Ecol Sociobiol 34:257-265

Bensch S, Hasselquist D (1991) Territory infidelity in the polygynous great reed warbler Acrocephalus arundinaceus: the effect of variation in territory attractiveness. J Anim Ecol 60:857-871

Bielański W, Solarz W, Zając T (2005) Effect of patch size on habitat loss in sedge warbler Acrocephalus schoenobaenus in the Middle Nida Wetlands (southern Poland). Nat Conserv 61:43-51

Bollinger EK, Gavin TA (1989) The effects of site quality on breeding-site fidelity in Bobolinks. Auk 106:584-594

Bried J, Jouventin P (1998) Why do Lesser Sheathbills Chionis minor switch territory? J Avian Biol 29:257-265

Buchanan KL, Catchpole CK (1997) Female choice in the sedge warbler, Acrocephalus schoenobaenus: multiple cues from song and territory quality. Proc R Soc Lond B Biol Sci 264:521-526

Currie D, Thompson DBA, Burke T (2000) Patterns of territory settlement and consequences for breeding success in the Northern Wheatear Oenanthe oenanthe. Ibis 142:389-398

Doligez B, Danchin E, Clobert J (2002) Public information and breeding habitat selection in a wild bird population. Science 297:1168-1170

Doligez D, Pärt T, Danchin E, Clobert J, Gustafsson L (2004) Availability and use of public information and conspecific density for settlement decisions in the collared flycatcher. J Anim Ecol 73:75-87

Ens BJ, Weissing FJ, Drent RH (1995) The despotic distribution and deferred maturity: two sides of the same coin. Am Nat 146:625650 
Forero MG, Donazar JA, Blas J, Hiraldo F (1999) Causes and consequences of territory change and breeding dispersal distance in the black kite. Ecology 80:1298-1310

Gill SA, Stutchbury BJM (2006) Long-term mate and territory fidelity in neotropical buff-breasted wrens (Thryothorus leucotis). Behav Ecol Sociobiol 61:245-253

Gonzalez-Solis J, Becker PH, Jover L, Ruiz X (2004) Individual changes underlie age-specific pattern of laying date and egg-size in female common terns (Sterna hirundo). J Ornithol 145:129-136

Haas CA (1998) Effects of prior nesting success on site fidelity and breeding dispersal: an experimental approach. Auk 115:929-936

Hoover JP (2003) Decision rules for site fidelity in a migratory bird, the prothonotary warbler. Ecology 84:416-430

Hopp SL, Kirby A, Boone CA (1999) Banding returns, arrival pattern, and site fidelity of white-eyed vireos. Wilson Bull 111:46-55

Howlett JS, Stutchbury BJM (2003) Determinants of between-season site, territory, and mate fidelity in hooded warblers (Wilsonia citrina). Auk 120:457-465

Kokko H, Lindstrom J, Alatalo RV, Rintamaki PT (1998) Queuing for territory positions in the lekking black grouse (Tetrao tetrix). Behav Ecol 9:376-383

Kokko H, Sutherland WJ (2001) Ecological traps in changing environments: ecological and evolutionary consequences of a behaviourally mediated Allee effect. Evol Ecol Res 3:537-551

Korpimäki E (1993) Does nest-hole quality, poor breeding success or food depletion drive the breeding dispersal of Tengmalm's owls? J Anim Ecol 62:606-613

Krebs JR (1971) Territory and breeding density in the great tit, Parus major L. Ecology 52:2-22

Krebs JR (1982) Territorial defence in the great tit (Parus major): do residents always win? Behav Ecol Sociobiol 11:185-194

Król W, Solarz W, Zając T (2002) Breeding biology of sedge warbler Acrocephalus schoenobaenus in the river Nida wetlands (Poland). Biologia 57:617-625

Lanyon SM, Thompson CF (1986) Site fidelity and habitat quality as determinants of settlement pattern in male painted buntings. Condor 88:206-210

Low M, Pärt T, Forslund P (2007) Age-specific variation in reproduction is largely explained by the timing of territory establishment in the New Zealand stitchbird Notiomystis cincta. J Anim Ecol 76:459-470

Marshall RC, Buchanan KL, Catchpole CK (2003) Sexual selection and individual genetic diversity in a songbird. Proc R Soc Lond B Biol Sci 270:S248-S250

Mauck RA, Huntington CE, Grubb TC Jr (2004) Age-specific reproductive success: evidence for the selection hypothesis. Evolution 58:880-885

McPeek MA, Rodenhouse NL, Holmes RT, Sherry TW (2001) A general model of site-dependent population regulation: population-level regulation without individual-level interactions. Oikos 94:417-424

Misenhelter MD, Rotenberry JT (2000) Choices and consequences of habitat occupancy and nest site selection in sage sparrows. Ecology 81:2892-2901

Morton ES, Derrickson KC, Stutchbury BJM (2000) Territory switching behaviour in a sedentary tropical passerine, the dusky antbird (Cercomacra tyrannina). Behav Ecol 11:648-653

Muller KL, Stamps JA, Krishnan VV, Willits NH (1997) The effects of conspecific attraction and habitat quality on habitat selection in territorial birds (Troglodytes aedon). Am Nat 150:650-661

Newton I (ed) (1992) Lifetime reproduction in birds. Academic Press, London

Newton I (1998) Population limitation in birds. Academic Press, London
Nilsson SG, Johnsson K, Tjernberg M (1991) Is avoidance by black woodpeckers of old nest holes due to predators? Anim Behav 41:439-441

Ortega YK, McKelvey KS, Six DL (2006) Invasion of an exotic forb impacts reproductive success and site fidelity of a migratory songbird. Oecologia 149:340-351

Petit LJ, Petit DR (1996) Factors governing habitat selection by prothonotary warblers: field tests of the Fretwell-Lucas models. Ecol Monogr 66:367-387

Pulliam RH, Danielson BJ (1991) Sources, sinks, and habitat selection: a landscape perspective on population dynamics. Am Nat 142:42-58

Robertson BA, Hutto RL (2006) A framework for understanding ecological traps and an evaluation of existing ecological evidence. Ecology 87:1075-1085

Rodenhouse NL, Sherry TW, Holmes RT (1997) Site-dependent regulation of population size: a new synthesis. Ecology 78:2025-2042

Sergio F, Newton I (2003) Occupancy as a measure of territory quality. J Anim Ecol 72:857-865

Shields WM (1984) Factors affecting nest and site fidelity in Adirondack barn swallows (Hirundo rustica). Auk 101:780-789

Shochat E, Patten MA, Morris DW, Reinking DL, Wolfe DH, Sherrod SK (2005) Ecological traps in isodars: effects of tallgrass prairie management on bird nest success. Oikos 111:159-169

Sonerud GA (1985) Nest hole shift in Tengmalm's owl Aegolius funereus as defense against nest predation involving long-term memory in the predator. J Anim Ecol 54:179-192

Sonerud GA (1993) Reduced predation by nest box relocationdifferential effect on Tengmalm's owl nests and artificial nests. Ornis Scand 24:249-253

Sorace A, Petrassi F, Consiglio C (2004) Long-distance relocation of nestboxes reduces nest predation by pine marten Martes martes. Bird Study 51:119-124

Stamps JA (1988) Conspecific attraction and aggregation in territorial species. Am Nat 131:329-347

Stamps JA (1991) The effect of conspecifics on habitat selection in territorial species. Behav Ecol Sociobiol 28:29-36

Switzer PV (1993) Site fidelity in predictable and unpredictable habitats. Evol Ecol 7:533-555

Tobias J (1997) Asymmetric territorial contests in the European robin: the role of settlement costs. Anim Behav 54:9-21

Valone TJ, Templeton JJ (2002) Public information for the assessment of quality: a widespread social phenomenon. Phil Trans R Soc Lond B 357:1549-1557

Wesołowski T (2006) Nest-site re-use: marsh tit Poecile palustris decisions in a primeval forest. Bird Study 53:199-204

Wiens JA, Rotenberry JT, van Horne B (1986) A lesson in the limitations of field experiments: shrubsteppe birds and habitat alteration. Ecology 67:365-376

Zając T (2010) Settlement mechanisms in males of sedge warbler Acrocephalus schoenobaenus. Studia Naturae 56:1-133 (in Polish with English summary)

Zając T, Solarz W, Bielański W (2006) Adaptive settlement in sedge warblers Acrocephalus schoenobaenus - focus on the scale of individuals. Acta Oecol 29:123-134

Zając T, Solarz W, Bielański W (2008a) Site-dependent population dynamics: the influence of spatial habitat heterogeneity on individual fitness in the sedge warbler Acrocephalus schoenobaenus. J Avian Biol 39:206-214

Zając T, Solarz W, Bielański W (2008b) On the song resumption, polyterritorial behaviour and their population context in sedge warbler Acrocephalus schoenobaenus. J Ornithol 149:49-57 